\title{
BMJ Open Meta-analysis: the effects of smoking on the disposition of two commonly used antipsychotic agents, olanzapine and clozapine
}

\author{
Yoshiyuki Tsuda, ${ }^{1}$ Junji Saruwatari, ${ }^{1}$ Norio Yasui-Furukori ${ }^{2}$
}

To cite: Tsuda $Y$, Saruwatari J, YasuiFurukori N. Meta-analysis: the effects of smoking on the disposition of two commonly used antipsychotic agents, olanzapine and clozapine. BMJ Open 2014;4:e004216. doi:10.1136/bmjopen-2013004216

- Prepublication history and additional material for this paper is available online. To view these files please visit the journal online (http://dx.doi.org/10.1136/ bmjopen-2013-004216).

Received 10 October 2013 Revised 3 February 2014 Accepted 10 February 2014

\section{CrossMark}

\section{${ }^{1}$ Division of Pharmacology and Therapeutics, Graduate School of Pharmaceutical Sciences, Kumamoto University, Kumamoto, Japan ${ }^{2}$ Department of Neuropsychiatry, Hirosaki University School of Medicine, Hirosaki, Japan}

\section{Correspondence to} Dr Junji Saruwatari; junsaru@gpo.kumamoto-u. ac.jp

\section{ABSTRACT}

Objective: To clarify the effects of smoking on the disposition of two commonly used antipsychotics, olanzapine and clozapine, and to create standards to adjust the doses of these drugs in clinical practice based on the smoking status.

Design: A meta-analysis was conducted by searching MEDLINE, Scopus and the Cochrane Library for relevant prospective and retrospective studies.

Included studies: We included the studies that investigated the effects of smoking on the concentration to dose (C/D) ratio of olanzapine or clozapine.

Primary outcome measure: The weighted mean difference was calculated using a DerSimonian-Laird random effects model, along with $95 \% \mathrm{Cl}$.

Results: Seven association studies, comprising 1094 patients (652 smokers and 442 non-smokers) with schizophrenia or other psychiatric disorders, were included in the meta-analysis of olanzapine. The $C / D$ ratio was significantly lower in smokers than in non-smokers $(p<0.00001)$, and the mean difference was $-0.75(\mathrm{ng} / \mathrm{mL}) /(\mathrm{mg} /$ day $)(95 \% \mathrm{Cl}$ -0.89 to -0.61 ). Therefore, it was estimated that if 10 and $20 \mathrm{mg} /$ day of olanzapine would be administered to smokers, about 7 and $14 \mathrm{mg} /$ day, respectively, should be administered to non-smokers in order to obtain the equivalent olanzapine concentration. Four association studies of clozapine were included in the meta-analysis of clozapine, comprising 196 patients (120 smokers and 76 nonsmokers) with schizophrenia or other psychiatric disorders. The $C / D$ ratio was significantly lower in smokers than in non-smokers $(p<0.00001)$, and the mean difference was $-1.11(\mathrm{ng} / \mathrm{mL}) /(\mathrm{mg} /$ day) $(95 \%$ $\mathrm{Cl}-1.53$ to -0.70 ). Therefore, it was estimated that if 200 and $400 \mathrm{mg} /$ day of clozapine would be administered to smokers, about 100 and $200 \mathrm{mg} /$ day, respectively, should be administered to nonsmokers.

Conclusions: We suggest that the doses of olanzapine and clozapine should be reduced by $30 \%$ and $50 \%$, respectively, in non-smokers compared with smokers in order to obtain an equivalent olanzapine or clozapine concentration.

\section{Strengths and limitations of this study}

- The major strength of this study is that it clarifies the effects of smoking on the olanzapine and clozapine concentrations in a large population and provides standards that can be used to regulate the dosage of olanzapine and clozapine in clinical practice based on the patient's smoking status.

- The major limitations of the present study are that we could not use another search engine, for example, EMBASE, and also we could not include the literature published in other languages (not in English) or the data regarding other confounding factors, such as the age, weight, gender, alcohol consumption and how much the participant smoked. Additionally, this meta-analysis standardised pharmacokinetic parameters to concentration to dose ratios, and therefore only seven studies for olanzapine and four studies for clozapine could be included.

\section{INTRODUCTION}

Olanzapine is an atypical antipsychotic drug approved for the treatment of schizophrenia and mania and for preventing the recurrence of bipolar disorders. ${ }^{1}$ Olanzapine is a thienobenzodiazepine derivate, which shows potent antagonism at $\mathrm{D}_{1-4}$ dopaminergic receptors, as well as $5-\mathrm{HT}_{2 \mathrm{~A}}$ and $5-\mathrm{HT}_{2 \mathrm{C}}$ serotonergic, $\alpha_{1}$-adrenergic, muscarinic and $\mathrm{H}_{1}$ histamine receptors. ${ }^{2}$ Olanzapine is extensively metabolised in the liver, mainly via cytochrome $\mathrm{P} 450$ (CYP) 1A2, but also via CYP2D6, CYP3A4, flavin-containing monooxygenase (FMO) and glucuronidation. ${ }^{2}$ Among these enzymes, CYP1A2 accounts for approximately 50-60\% of olanzapine metabolism. ${ }^{2}$

Clozapine is the prototype atypical antipsychotic, and it belongs to the chemical class of the dibenzodiazepines. ${ }^{1}$ Clozapine has much greater antagonistic activity on $\mathrm{D}_{4}$ 
than $\mathrm{D}_{2}$ dopaminergic receptors. It also shows a potent antagonism of $5-\mathrm{HT}_{2 \mathrm{~A}}$ and $5-\mathrm{HT}_{2 \mathrm{C}}$ serotonergic, $\alpha_{1}$-adrenergic, muscarinic and $\mathrm{H}_{1}$ histamine receptors. ${ }^{1}$ Clozapine has been widely used following its introduction, because it induces relatively few extrapyramidal effects, and it shows therapeutic benefits for patients who have failed to respond to other agents. ${ }^{3}$ Clozapine is absorbed rapidly and undergoes extensive hepatic metabolism. ${ }^{4}$ Various lines of evidence indicate that CYP1A2 and CYP3A4 play a significant role in the $\mathrm{N}$-oxidation and $\mathrm{N}$-demethylation of the compound, whereas CYP2D6 plays a minor role in $N$-demethylation. ${ }^{14}$

The prevalence of smoking is twofold to threefold higher in patients with schizophrenia than in the general population, and about $58-88 \%$ of patients with schizophrenia are current smokers. ${ }^{5}$ Cigarette smoke increases the activity of CYP1A2, thus decreasing the blood concentrations of many drugs, including olanzapine and clozapine. ${ }^{6}$

Citrome $e t a l^{7} \quad(\mathrm{n}=380)$ reported that the olanzapine concentrations were significantly lower in smokers with schizophrenia than in non-smokers. Previous clinical studies with small numbers of patients with schizophrenia reported that smokers had an approximately fivefold lower dose-corrected steady-state plasma olanzapine concentration and a lower decrease in the Brief Psychiatric Rating Scale-total score than non-smokers. ${ }^{8}{ }^{9}$ Meanwhile, although the relationship between the clozapine concentration and clinical outcome is controversial, ${ }^{10-12}$ it was also reported that smokers who were treated with clozapine suffered side effects (ie, auditory hallucinations, hallucinations, hypersalivation, drowsiness, clonic seizures, convulsions and unconsciousness) after smoking cessation. ${ }^{4}$ 13-16

Many studies about the effects of smoking on the disposition of olanzapine and clozapine have been undertaken, but no definitive agreement regarding the dose adjustment in clinical practice based on the patient's smoking status has been reached. There are several reasons for the slow progress in making the smoking-associated dosage selection: (1) the sample sizes of the previous studies were small; (2) each study used different pharmacokinetic (PK) parameters (eg, plasma concentration, plasma concentration to dose (C/ D) ratio, clearance $(\mathrm{CL})$ ), and the degree of the effect of smoking on the dispositions of olanzapine or clozapine was different between studies. Therefore, a meta-analysis has been needed to overcome the limitations of the previous studies and to determine the degree of the effects of smoking on the disposition of olanzapine and clozapine, in order to develop standards that can be used to adjust the doses of olanzapine and clozapine used in clinical practice based on the smoking status of the patient.

In this study, we performed a meta-analysis of the effects of smoking on the disposition of olanzapine and clozapine.

\section{METHODS}

\section{Study selection}

A preliminary search of the literature covering the period from 1946 to August 2012 was undertaken to identify publications related to the effects of smoking on the disposition of olanzapine and clozapine. Electronic databases, including MEDLINE, Scopus and the Cochrane Library, were initially searched using six terms, in which either 'olanzapine' or 'clozapine' was paired with 'smoking' or 'cigarette' or 'tobacco' or 'smoke'. We excluded studies other than English publications, and studies not performed on human participants, after the search. The inclusion criteria were as follows: (1) published in a peer-reviewed journal; (2) contained the mean $\mathrm{C} / \mathrm{D}$ ratios $(\mathrm{ng} / \mathrm{mL}) /(\mathrm{mg} /$ day $)$ of olanzapine or clozapine, and their SD in smokers and non-smokers, respectively, and we requested data from the author(s) if either the mean $\mathrm{C} / \mathrm{D}$ ratios or the $\mathrm{SD}$ was not described and (3) the data were from participants who had received olanzapine or clozapine for at least a week. In this study, smokers were defined as participants who were currently smoking. Additionally, we divided the selected publications into two groups, that is, olanzapine and clozapine study groups (figure 1).

The review and analysis were conducted using the Preferred Reporting Items for Systematic Reviews and Meta-analyses (PRISMA) Statement as a guide. ${ }^{17}$ Two researchers (YT and JS) independently searched the literature. Once all the papers had been assessed, any discrepancies in the answers were identified and discussed between the scorers to reach a consensus on the single best option. Any points of assessment on which the scorers could not reach an agreement were resolved by a third scorer (NY-F). The data were extracted from each article using a standardised form including the first author, publication year and other information, as described in the following section.

\section{Data extraction}

The number of patients, the mean values of the $\mathrm{C} / \mathrm{D}$ ratios and the $\mathrm{SD}$ values of these ratios were extracted for smokers and non-smokers, respectively, from the selected publications. The $\mathrm{C} / \mathrm{D}$ ratios were standardised to be in the same units, that is, $(\mathrm{ng} / \mathrm{mL}) /(\mathrm{mg} /$ day $)$. When the values were not described or they were drawn on another scale $(\mathrm{eg},(\mathrm{ng} / \mathrm{mL}) /(\mathrm{mg} / \mathrm{kg}))$, we asked the author(s) to send us their data in the desired units. We tried to gather information by requesting it from 26 authors. Although five authors responded to our requests, the other 21 studies of olanzapine or clozapine could not be included due to a lack of information (the mean $\mathrm{C} / \mathrm{D}$ ratios and $\mathrm{SD}$ were not available for smokers and non-smokers, respectively, from 14 studies, the SD was not given in four studies, and the mean $\mathrm{C} / \mathrm{D}$ ratios were described on another scale, ie, $(\mathrm{ng} / \mathrm{ml})(\mathrm{mg} / \mathrm{kg})$, in three studies; figure 1$)$.

The characteristics of the studies included in this meta-analysis of the effects of smoking on the disposition of olanzapine or clozapine are shown in tables 1 and 2 . 
Figure 1 A flow chart of the study selection process. C/D, concentration to dose.

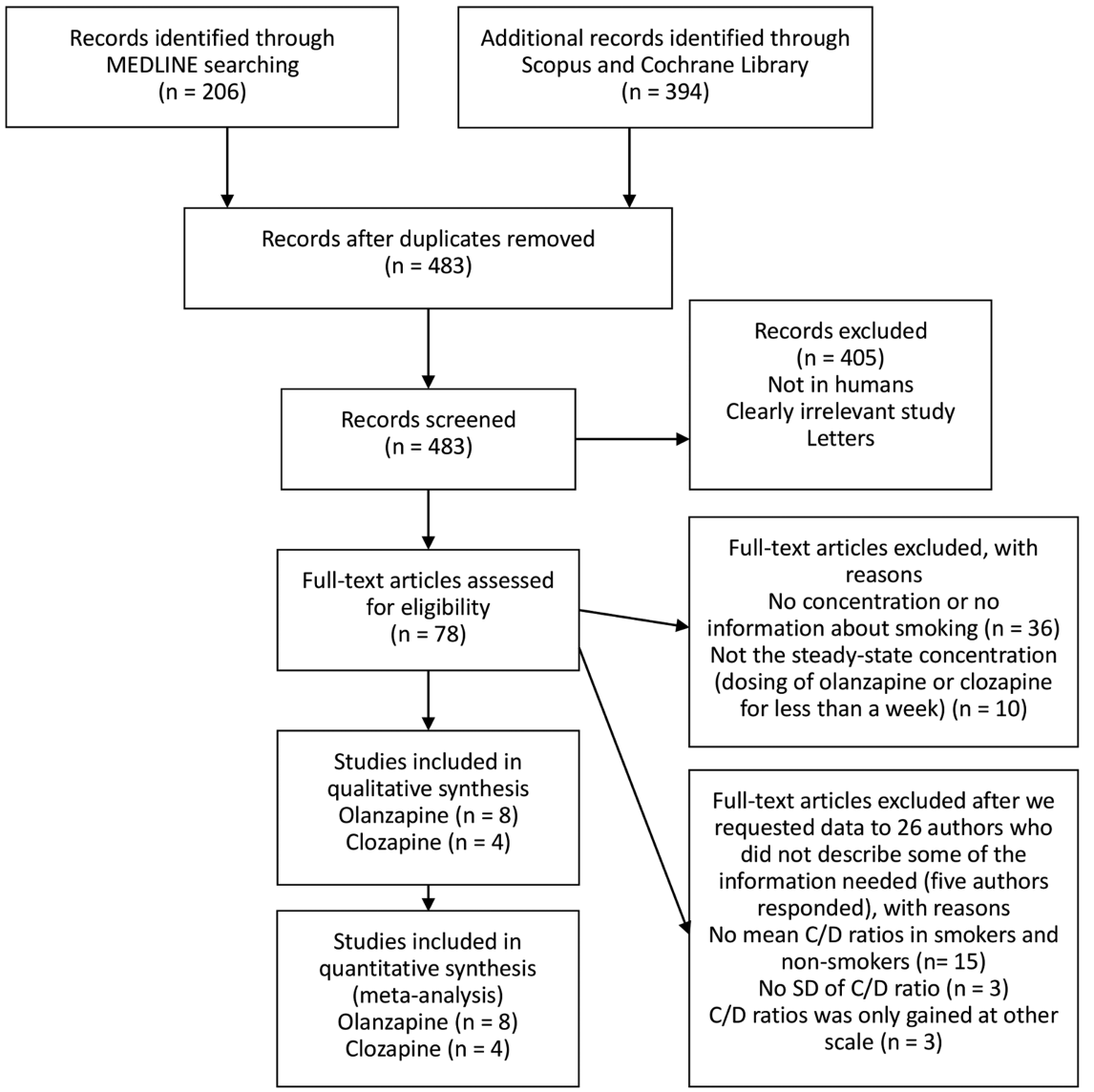

We systematically assessed several key points of study quality proposed by the MOOSE Collaboration. ${ }^{18}$ The quality of the included studies is shown in table 3 .

\section{Statistical analysis}

A meta-analysis using the weighted mean difference in the $\mathrm{C} / \mathrm{D}$ ratios of olanzapine or clozapine between smokers and non-smokers was performed using the Review Manager (RevMan) V.5.1 for Windows software program (Cochrane Collaboration, http://www.cc-ims. net/RevMan). Cochran's $\chi^{2}$-based Q-statistic test was applied to assess the between-study heterogeneity. The weighted mean difference was calculated using the DerSimonian-Laird ${ }^{19}$ random effects models, along with

Table 1 Characteristics of the included olanzapine studies

\begin{tabular}{|c|c|c|c|c|c|c|c|}
\hline Study & Country & Study design & $\begin{array}{l}\text { Number of } \\
\text { participants } \\
\text { (smokers) }\end{array}$ & $\begin{array}{l}\text { Gender } \\
\text { (male/ } \\
\text { female) }\end{array}$ & Disease & Diagnosis & $\begin{array}{l}\text { Age } \\
\text { (meantSD } \\
\text { or range) }\end{array}$ \\
\hline Haslemo et al ${ }^{21}$ & Norway & $\begin{array}{l}\text { Retrospective } \\
\text { study }\end{array}$ & $40(31)$ & $29 / 11$ & Schizophrenia & Unknown & $40-71$ \\
\hline Nozawa et al ${ }^{22}$ & Japan & $\begin{array}{l}\text { Retrospective } \\
\text { study }\end{array}$ & $51(16)$ & $34 / 17$ & Schizophrenia & DSM-IV & $32.6 \pm 9.6$ \\
\hline Bigos et $a^{23}$ & USA & Prospective study & $406(267)$ & $289 / 117$ & Schizophrenia & DSM-IV & $42 \pm 7.9$ \\
\hline Laika et $a f^{4}$ & Germany & $\begin{array}{l}\text { Retrospective } \\
\text { study }\end{array}$ & $73(30)$ & $36 / 37$ & $\begin{array}{l}\text { Schizophrenia, Mood } \\
\text { disorder }\end{array}$ & ICD-10 & $41.7 \pm 14.7$ \\
\hline Citrome et $a l^{7}$ & USA & Prospective study & $380(257)$ & $265 / 115$ & $\begin{array}{l}\text { Schizophrenia, } \\
\text { Schizoaffective disorder }\end{array}$ & DSM-IV & $18-60$ \\
\hline Spina et $a l^{25}$ & Italy & Prospective study & $18(8)$ & $10 / 8$ & $\begin{array}{l}\text { Bipolar disorder, } \\
\text { Schizoaffective disorder }\end{array}$ & DSM-IV & $39.3 \pm 8.6$ \\
\hline Skogh et $a{ }^{26}$ & Sweden & $\begin{array}{l}\text { Retrospective } \\
\text { study }\end{array}$ & $37(10)$ & $25 / 12$ & $\begin{array}{l}\text { Schizophrenia, } \\
\text { Schizoaffective disorder }\end{array}$ & DSM-IV & $23-50$ \\
\hline Haslemo et $a^{27}$ & Norway & $\begin{array}{l}\text { Retrospective } \\
\text { study }\end{array}$ & $129(64)$ & $0 / 129$ & Unknown & Unknown & $18-40$ \\
\hline
\end{tabular}


Table 2 Characteristics of the included clozapine studies

\begin{tabular}{|c|c|c|c|c|c|c|c|}
\hline Study & Country & Study design & $\begin{array}{l}\text { Number of } \\
\text { participants } \\
\text { (smokers) }\end{array}$ & $\begin{array}{l}\text { Gender } \\
\text { (male/ } \\
\text { female) }\end{array}$ & Disease & Diagnosis & $\begin{array}{l}\text { Age } \\
\text { (mean } \pm S D \\
\text { or range) }\end{array}$ \\
\hline Dettling et $a^{28}$ & Germany & $\begin{array}{l}\text { Retrospective } \\
\text { study }\end{array}$ & $34(25)$ & $18 / 16$ & Schizophrenia & DSM-III-R & $33.7 \pm 10.6$ \\
\hline Palego et al ${ }^{29}$ & USA & $\begin{array}{l}\text { Retrospective } \\
\text { study }\end{array}$ & $49(22)$ & $25 / 24$ & $\begin{array}{l}\text { Bipolar disorder } \\
\text { schizophrenia, } \\
\text { Schizoaffective } \\
\text { disorder }\end{array}$ & DSM-IV & $\begin{array}{l}36.84 \pm 1.96 \\
(\mathrm{SE})\end{array}$ \\
\hline Weide et $a l^{30}$ & The Netherlands & $\begin{array}{l}\text { Retrospective } \\
\text { study }\end{array}$ & $80(45)$ & $51 / 29$ & Schizophrenia & Unknown & $18-86$ \\
\hline Haslemo et al, ${ }^{21}$ & Norway & $\begin{array}{l}\text { Retrospective } \\
\text { study }\end{array}$ & $33(28)$ & $21 / 12$ & Schizophrenia & Unknown & $28-62$ \\
\hline
\end{tabular}

$95 \% \mathrm{CI}$, to measure the strength of the association. In this study, we applied the random effects model for the comparisons, which is more conservative because of the possibility that the underlying effect differed across studies and populations. The weighted mean difference was also calculated when the studies were stratified according to the study design, that is, prospective or retrospective study. We used the $\mathrm{I}^{2}$ statistic to assess the heterogeneity of the results. Publication bias was assessed by visually examining a funnel plot with asymmetry and formally assessing publication bias with the Egger $e t a l$ 's test. ${ }^{20}$ The statistical significance level for all analyses was set at a two-sided value of $\mathrm{p}<0.05$.

\section{RESULTS}

Olanzapine: search results and study characteristics

Eight studies of olanzapine ${ }^{7}{ }^{21-27}$ met our criteria (figure 1). The studies included in this analysis for olanzapine are listed in table 1 . Since the study by Citrome et $a l^{7}$ was derived from a randomised clinical trial of 10 ,
20 and $40 \mathrm{mg}$ as the daily olanzapine dose in patients with schizophrenia or schizoaffective disorder, we divided its populations into three groups according to the respective olanzapine doses. Since the study by Spina et $a l^{25}$ focused on the effects of valproate on the olanzapine plasma concentrations, we extracted the C/D ratios of olanzapine at baseline (before taking valproate). The study by Haslemo et $a l^{27}$ focused on the effects of contraceptives on the serum concentration of olanzapine among female patients who were treated either with olanzapine alone or the combination of estradiol-containing contraceptives, so we requested the $\mathrm{C} / \mathrm{D}$ ratios in participants not using any contraceptives that can affect the CYP1A2 activity.

\section{Primary analyses of olanzapine}

The weighted mean difference was derived from all studies, comprising a total of 1134 patients (683 smokers and 451 non-smokers) with schizophrenia or other psychiatric disorders. The $\mathrm{C} / \mathrm{D}$ ratio was significantly lower in smokers than in non-smokers $(p<0.00001$; figure 2$)$,

Table 3 Quality of the included studies

\begin{tabular}{|c|c|c|c|c|c|c|c|c|}
\hline $\begin{array}{l}\text { First } \\
\text { author }\end{array}$ & $\begin{array}{l}\text { Publication } \\
\text { year }\end{array}$ & $\begin{array}{l}\text { Drug } \\
\text { treatment }\end{array}$ & $\begin{array}{l}\text { Number } \\
\text { of } \\
\text { smokers }\end{array}$ & $\begin{array}{l}\text { Diagnostic } \\
\text { criteria }\end{array}$ & $\begin{array}{l}\text { Treatment } \\
\text { duration }\end{array}$ & $\begin{array}{l}\text { Measurement of } \\
\text { blood drug } \\
\text { concentration }\end{array}$ & $\begin{array}{l}\text { Sampling } \\
\text { scheme }\end{array}$ & $\begin{array}{l}\text { Total } \\
\text { score }\end{array}$ \\
\hline Haslemo & 2006 & Olanzapine & Yes & NA & Yes & Yes & Yes & 4 \\
\hline Nozawa & 2008 & Olanzapine & Yes & Yes & Yes & Yes & NA & 4 \\
\hline Bigos & 2008 & Olanzapine & Yes & Yes & Yes & Yes & Yes & 5 \\
\hline Laika & 2009 & Olanzapine & Yes & Yes & Yes & Yes & Yes & 5 \\
\hline Citrome & 2009 & Olanzapine & Yes & Yes & Yes & Yes & Yes & 5 \\
\hline Spina & 2009 & Olanzapine & Yes & Yes & Yes & Yes & Yes & 5 \\
\hline Skogh & 2011 & Olanzapine & Yes & Yes & Yes & Yes & Yes & 5 \\
\hline Haslemo & 2011 & Olanzapine & Yes & NA & NA & Yes & Yes & 3 \\
\hline Dettling & 2000 & Clozapine & Yes & Yes & Yes & Yes & Yes & 5 \\
\hline Palego & 2002 & Clozapine & Yes & Yes & Yes & Yes & Yes & 5 \\
\hline Weide & 2003 & Clozapine & Yes & NA & Yes & Yes & Yes & 4 \\
\hline Haslemo & 2006 & Clozapine & Yes & NA & Yes & Yes & Yes & 4 \\
\hline
\end{tabular}


and the mean difference was $-0.83(\mathrm{ng} / \mathrm{mL}) /(\mathrm{mg} /$ day $)$ (95\% CI -1.04 to -0.63$)$. Although there was no significant publication bias $(\mathrm{p}=0.26)$, significant heterogeneity was observed $\left(I^{2}=50, p=0.04\right)$. Since we included two studies by the same authors, we excluded the older study $^{21}$ in the subsequent analyses to reduce the heterogeneity.

The analysis from the seven studies showed that there was no significant heterogeneity among the mean differences $\left(I^{2}=11 \%, p=0.35\right.$; figure $\left.3 A\right)$. The weighted mean difference was derived from all studies, comprising 1094 patients (652 smokers and 442 non-smokers) with schizophrenia or other psychiatric disorders. The C/D ratio was significantly lower in smokers than in nonsmokers $(\mathrm{p}<0.00001$; figure $3 \mathrm{~A})$, and the mean difference was $-0.75(\mathrm{ng} / \mathrm{mL}) /(\mathrm{mg} /$ day $)(95 \%$ CI -0.89 to $-0.61)$. No significant publication bias was shown using the Egger test in the studies of olanzapine $(p=0.282)$. The funnel plot also suggested that publication bias was unlikely (see online supplementary figure S1).

\section{Subgroup analyses of olanzapine}

\section{Prospective studies}

We conducted subgroup analyses to confirm the precision of the primary analyses. Of the seven included studies of olanzapine, three were prospective studies, while four were retrospective studies. In the prospective studies (532 smokers and 272 non-smokers), the C/D ratio was significantly lower in smokers than in nonsmokers $(\mathrm{p}<0.00001$; figure $3 \mathrm{~B})$, and the mean difference was $-0.73(\mathrm{ng} / \mathrm{mL}) /(\mathrm{mg} /$ day $)(95 \%$ CI -0.95 to -0.50$)$.

\section{Retrospective studies}

In the retrospective studies (120 smokers and 170 nonsmokers), the $\mathrm{C} / \mathrm{D}$ ratio was significantly lower in smokers than in non-smokers $(\mathrm{p}<0.00001$; figure $3 \mathrm{C})$, and the mean difference was $-0.84(\mathrm{ng} / \mathrm{mL}) /(\mathrm{mg} /$ day $)$ (95\% CI -1.08 to -0.59$)$.

\section{Clozapine: search results and study characteristics}

Four studies regarding the clozapine disposition ${ }^{21} 28-30$ met our criteria, all of which were retrospective studies (figure 1). The clozapine studies included in this analysis are listed in table 2.

\section{Analyses of clozapine}

There was no significant heterogeneity among the mean differences $\left(\mathrm{I}^{2}=33 \%, \mathrm{p}=0.22\right.$; figure 4$)$. The weighted mean difference was derived from all studies, comprising 196 patients (120 smokers and 76 non-smokers) with schizophrenia or other psychiatric disorders. The C/D ratio was significantly lower in smokers than in nonsmokers $(\mathrm{p}<0.00001$; figure 4$)$, and the mean difference was $-1.11 \quad(\mathrm{ng} / \mathrm{mL}) /(\mathrm{mg} /$ day $) \quad(95 \%$ CI -1.53 to $-0.70)$. No significant bias was shown using the Egger test for the clozapine studies $(\mathrm{p}=0.436)$. The funnel plot also suggested that publication bias was unlikely (see supplementary supplementary figure S2).

\section{DISCUSSION}

Smoking is a well-known cause of significant drug interactions in humans. ${ }^{31-33}$ The polyaromatic hydrocarbons in cigarette smoke are known to induce CYP1A2, ${ }^{34}$ and therefore cigarette smoking can affect the disposition of drugs that are metabolised by CYP1A2, such as olanzapine and clozapine. The prevalence of current smokers is higher in patients with schizophrenia than in the general population. ${ }^{5}$ However, at present, there are no definitive data regarding the dose adjustments of olanzapine and clozapine in clinical practice based on the patient's smoking status. This is the first meta-analysis to clarify the effects of smoking on the disposition of these drugs.

\section{Olanzapine}

In the meta-analysis of olanzapine, 1094 patients (652 smokers and 442 non-smokers) from seven clinical studies of olanzapine were evaluated. The results showed that the $\mathrm{C} / \mathrm{D}$ ratio of olanzapine was $0.75(\mathrm{ng} / \mathrm{mL}) /$ $(\mathrm{mg} /$ day) lower in smokers than in non-smokers. The subgroup analyses (prospective/retrospective studies) also showed similar results. Approximately $85 \%$ of the oral olanzapine dose is absorbed, but as about $40 \%$ is

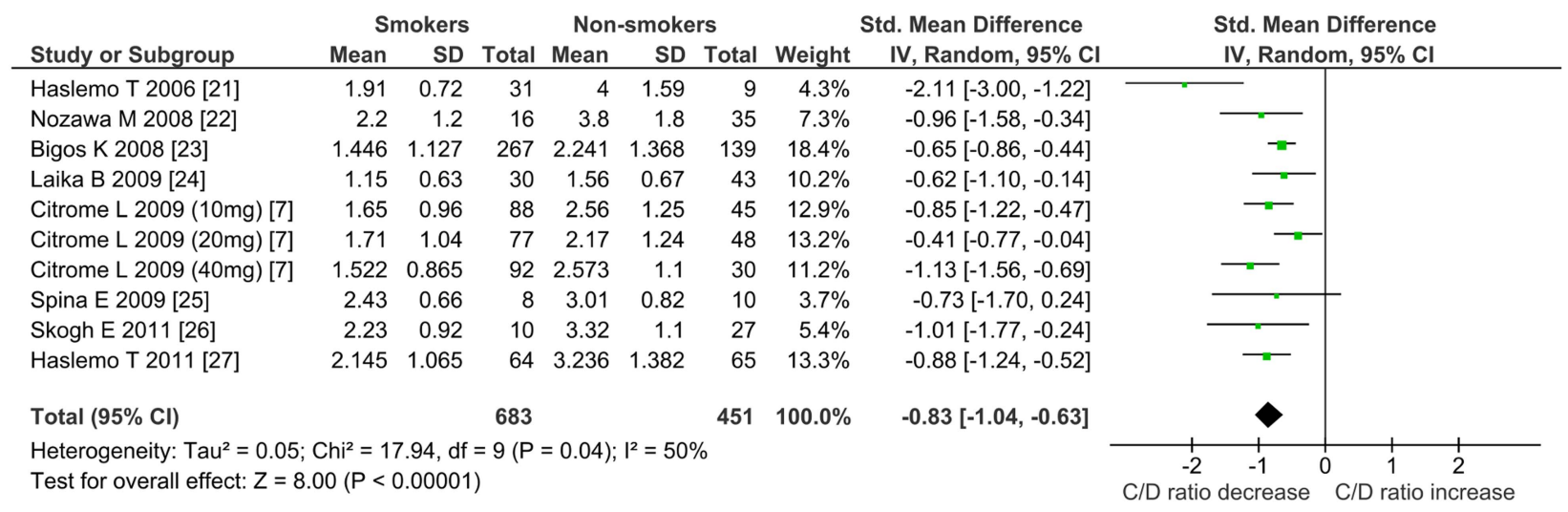

Figure 2 Forest plot olanzapine $(n=8)$. 
(a)

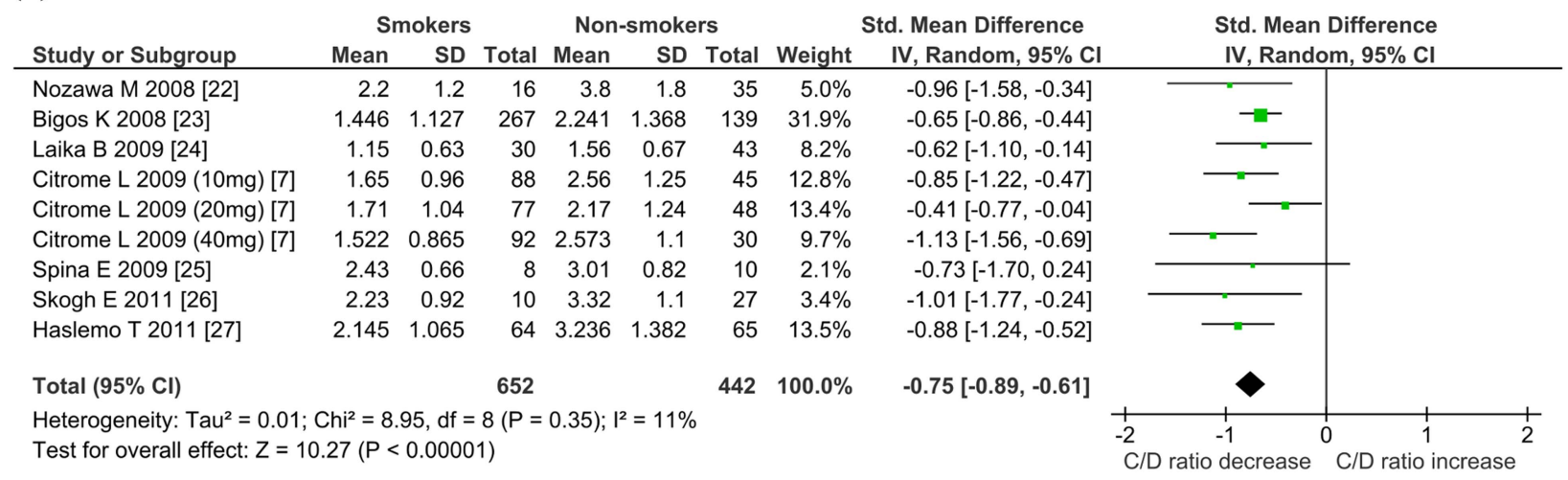

(b)

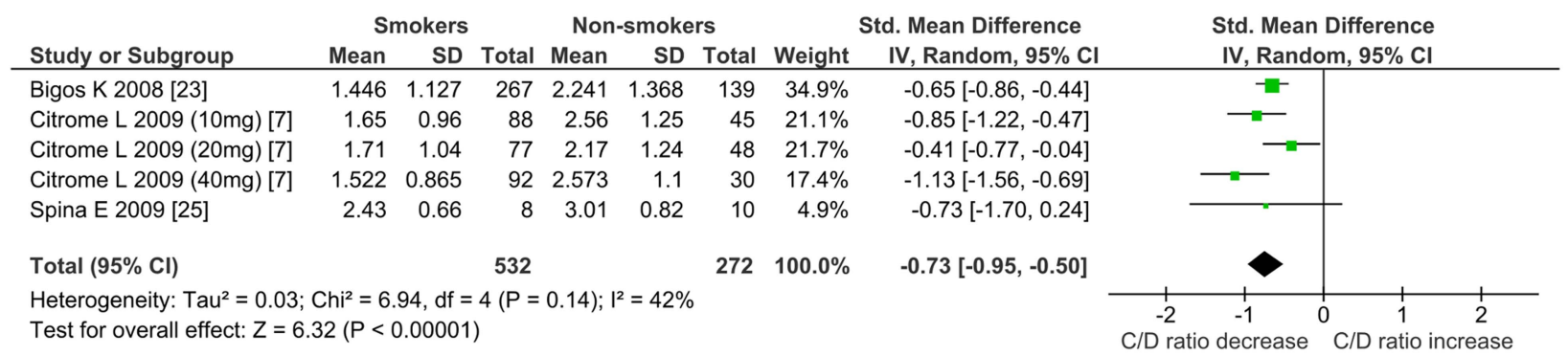

(c)

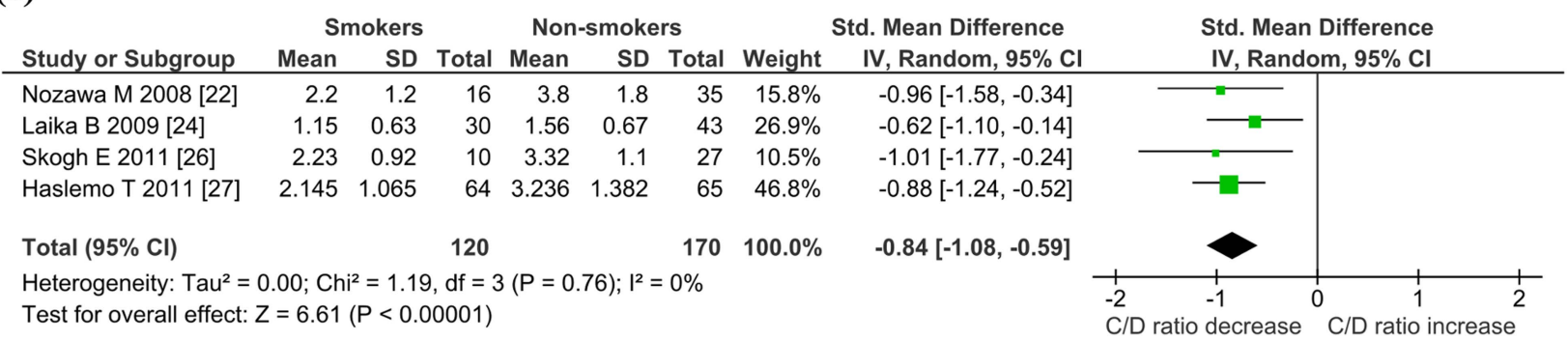

Figure 3 Forest plot $(A)$ olanzapine study $(n=7)(B)$ prospective olanzapine study $(n=3)(C)$ retrospective olanzapine study $(n=4)$.

inactivated by first-pass hepatic metabolism, its oral bioavailability is about $60 \% .^{1}$ The mean half-life, mean apparent drug plasma CL and mean apparent volume of distribution of olanzapine were $33 \mathrm{~h}, 26 \mathrm{~L} / \mathrm{h}$ and $1150 \mathrm{~L}$ in healthy individuals. ${ }^{35}$ Previous clinical studies demonstrated that the $\mathrm{C} / \mathrm{D}$ ratio of olanzapine correlated significantly with a decrease in the Brief Psychiatric Rating Scale. ${ }^{8}$ The association between the clinical outcome and the plasma olanzapine concentration is clearly curvilinear, with clinical efficacy being approximately associated with a plasma olanzapine concentration range of $20-50 \mathrm{ng} / \mathrm{mL} .^{1}$ Bigos et $a l^{33}(\mathrm{n}=523)$ analysed the population PKs of olanzapine, and they determined that sex, smoking and race contribute to the variability in olanzapine CL. The study also demonstrated that smoking increased the olanzapine CL by $55 \%$, while also incorporating other confounding factors. Based on the findings of the present study, it was estimated that if 10

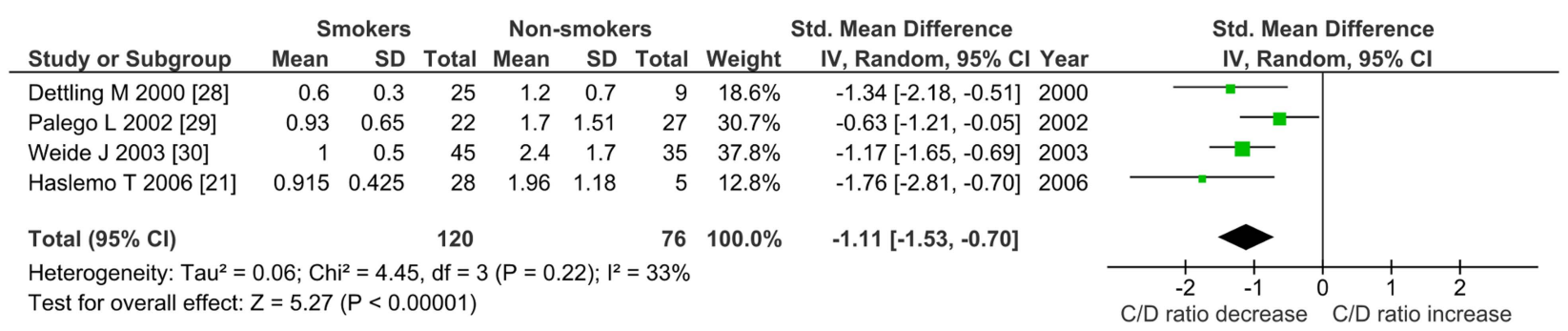

Figure 4 Forest plot clozapine $(n=4)$. 
and $20 \mathrm{mg}$ /day of olanzapine (the usual doses in Japan) would be administered to smokers, about 7 and $14 \mathrm{mg}$ / day, respectively, should be administered to non-smokers in order to obtain the equivalent olanzapine concentrations. These findings imply that the daily doses of olanzapine should be reduced by $30 \%$ in non-smokers compared with smokers.

\section{Clozapine}

In the meta-analysis of clozapine, 196 patients (smokers 120 , non-smokers 76 ) from four clinical studies were evaluated. The results showed that the $\mathrm{C} / \mathrm{D}$ ratio of clozapine was $1.11(\mathrm{ng} / \mathrm{mL}) /(\mathrm{mg} /$ day $)$ lower in smokers than in non-smokers. After oral administration of clozapine, the drug is absorbed rapidly. Only $27-50 \%$ of the dose reaches the systemic circulation unchanged, because of extensive first-pass metabolism. ${ }^{1}$ There is a wide interpatient variability in PK parameters of clozapine. ${ }^{1}$ The mean half-life of clozapine ranges from 9 to $17 \mathrm{~h} .{ }^{1}$ The plasma $\mathrm{CL}$ of clozapine was reported to be between 9 and $53 \mathrm{~L} /$ $\mathrm{h}$, and the volume of distribution of clozapine was between 2 and $7 \mathrm{~L} / \mathrm{kg} .{ }^{1}$ The steady-state plasma concentrations of clozapine are reached after 7-10 days of dosing. ${ }^{1}$ The relationship between clozapine concentration and clinical outcome is controversial. According to the study by Spina $e t a l,{ }^{11}$ a receiver operating characteristics analysis showed that a clozapine concentration cut-off value of $350 \mathrm{ng} / \mathrm{mL}$ distinguished responders and non-responders with a sensitivity of $72 \%$ and a specificity of $70 \%$. On the other hand, it has been suggested that the clozapine concentration does not correlate with the decrease in the Brief Psychiatric Rating Scale. ${ }^{10} 12$

A recent review summarised the previous studies regarding the relationships between the clozapine concentrations and clinical response, and suggested that clozapine levels above $250-400 \mathrm{ng} / \mathrm{mL}$ are associated with an increased chance of a clinical response. ${ }^{36}$ Moreover, clozapine doses exceeding 500-600 mg/day of clozapine could carry an increased risk of seizures. ${ }^{36}$ Because the smokers who were treated with clozapine were reported to suffer from serious central nervous side effects after smoking cessation, ${ }^{4}{ }^{13-16}$ it is necessary to regulate the clozapine dosage carefully when smokers stop smoking or decrease the amount of smoking. Li et al (2012) applied non-linear mixed-effect modelling to characterise the PKs of clozapine in Chinese patients. ${ }^{37}$ In the final model, sex and the smoking status were identified as significant covariates for the CL of clozapine and norclozapine, ${ }^{37}$ and smokers had a 1.45-fold higher CL of clozapine than non-smokers. ${ }^{37}$ Based on the findings of the present study, it was estimated that if 200 and $400 \mathrm{mg} /$ day of clozapine (the usual doses in Japan) would be administered to smokers, about 100 and $200 \mathrm{mg} /$ day, respectively, should be administered to nonsmokers in order to obtain the equivalent clozapine concentrations. These findings imply that the daily doses of clozapine should be reduced by $50 \%$ in non-smokers compared with smokers.
Other factors affecting the disposition of olanzapine and clozapine

Many previous clinical studies have reported that sex, race, age, comedication and the genotype could affect the disposition of olanzapine and clozapine. ${ }^{23}{ }^{37-47}$ Since oestrogen is known to inhibit the activity of CYP1A2 $2{ }^{23}$ it is not surprising that the CL of olanzapine and clozapine was reported to be lower in women than in men. ${ }^{23}$ Comedications are also known to affect the disposition of olanzapine and clozapine. Several drugs, such as fluoxetine and fluvoxamine, were reported to increase the blood concentration of olanzapine and/or clozapine through the inhibition of CYP1A2, CYP2D6, CYP3A4 and/or UDP-glucuronyltransferase $1 \mathrm{~A} 4 .{ }^{27} \quad 41 \quad 43 \quad 45 \quad 48$ Additionally, carbamazepine, phenobarbital and trimipramine were reported to decrease the blood concentrations of olanzapine and/or clozapine through the induction of CYP1A2 or CYP3A4. ${ }^{41} 4548{ }^{49}$ Race is known to be associated with variability in the CYP1A2 activity. Bigos et $a l^{23}$ reported that African-Americans cleared olanzapine faster than did other races (ie, Caucasians, Asians and Native Americans). Moreover, many genetic polymorphisms were reported to affect the disposition of olanzapine and clozapine. A recent review suggested that UGT1A4*3, CYP1A2 rs2472297, FMO3 K158-G308, FMO1*6, FMO1 rs7877 and CYP3A43 rs472660 polymorphisms all influence the olanzapine metabolism. ${ }^{50}$ Regarding clozapine, Lee et $a l^{44}$ showed that CYP1A2 rs2069521 and rs2069522 polymorphisms were significantly associated with the $\mathrm{C} / \mathrm{D}$ ratio of clozapine, and CYP2D6 rs1135840 was associated with the ratio of norclozapine and clozapine. Nevertheless, in the present study, there were insufficient data available to assess the effects of these factors on the disposition of olanzapine or clozapine. Moreover, the influence of smoking on the disposition of olanzapine and clozapine might be different among different patient populations (eg, the elderly, women, different diagnostic groups), but we could not conduct a meta-analysis for these populations.

\section{Strengths and limitations of the study}

The major strengths of this study are that it synthesised the previous studies with standardisation of the PK parameters to the $\mathrm{C} / \mathrm{D}$ ratios, clarified the degree of the effect of smoking on the $\mathrm{C} / \mathrm{D}$ ratios and provided standards that can be used to adjust the doses of olanzapine and clozapine in clinical practice based on the patient's smoking status.

On the other hand, there are several limitations to this meta-analysis. The major limitations of the present study are that we could not use another search engine, for example, EMBASE, due to lack of the access authority, and we could not include the literature published in other languages (not in English) or the data regarding other confounding factors, such as the age, weight, gender, alcohol consumption and how much the participant smoked. This meta-analysis standardised the PK parameters to $\mathrm{C} / \mathrm{D}$ ratios $(\mathrm{ng} / \mathrm{mL}) /(\mathrm{mg} /$ day $)$, and 
therefore only seven studies for olanzapine and four studies for clozapine could be included. In the present study, we excluded 10 reports (three for olanzapine and seven for clozapine) because the data were not from participants who had received olanzapine or clozapine for at least a week (figure 1). When the values were not described or they were given in another scale, we tried to gather information by requesting it from 26 authors, but only 5 responded to our requests. The other 9 studies of olanzapine and 12 studies of clozapine could not be included (regarding olanzapine, the mean C/D ratios of olanzapine and its SD were not available for smokers and non-smokers in seven studies; the SD was not given in two studies. Regarding clozapine, the mean $\mathrm{C} / \mathrm{D}$ ratios of clozapine and its SD were not available for smokers and non-smokers in seven studies; the mean $\mathrm{C} / \mathrm{D}$ ratios were provided in another scale, ie, $(\mathrm{ng} / \mathrm{mL})$ $(\mathrm{mg} / \mathrm{kg})$ in three studies and the SD was not given for two studies). Additionally, we excluded one study ${ }^{21}$ in the analyses of olanzapine in order to reduce the heterogeneity. These may have led to a selection bias. Furthermore, we included the three results from Citrome $e t a l^{7}$ independently, and therefore the correlation of these results should be verified using a random intercept in the mixed effects meta-analysis. When the three results were included separately in the meta-analysis, the weighted differences were not significantly different among the analyses (see supplementary figure S3). However, we could not apply the random intercept in the mixed effects meta-analysis, because we used the RevMan software program, which lacks this function for the analysis. In previous studies, the sum concentrations of clozapine and its metabolite, norclozapine, and the norclozapine to clozapine ratio were also used as a clinical outcome and an index of metabolic activity, respectively. ${ }^{1}$ However, we could not use these parameters for the present meta-analysis, because we used only the clozapine $\mathrm{C} / \mathrm{D}$ ratio in order to be able to include as many studies as possible and to develop simple standards that can be used in clinical practice.

The other limitation is that this meta-analysis simply divided participants into smokers and non-smokers, so the amount of smoking was not able to be taken into consideration. It has been suggested that the smoking-induced changes in hepatic CYP1A2 abundance are dependent on the daily cigarette consumption. ${ }^{51}$ Therefore, the differences in the amounts of smoking might have contributed to the variations in the influence of cigarette smoking on the disposition of olanzapine and clozapine among the studies included. Additionally, this meta-analysis could not confirm patient adherence. It was previously reported that up to $80 \%$ of patients with schizophrenia are at least partially non-adherent, ${ }^{52}$ and this might have affected the results. Although we included the studies that described that the participants had taken the drug for at least a week, we could not obtain any information regarding the adherence, because none of the studies clearly described this information. Finally, the use of comedications, which may affect the disposition of olanzapine or clozapine, could not be excluded. Six participants in the study by Laika $e t a l^{24}$ were taking carbamazepine and 21 participants in the study by Weide et $a l^{30}$ were taking carbamazepine or fluvoxamine. These drugs are known to affect the activity of CYP1A2 and/or CYP3A4, which is also involved in the metabolism of olanzapine and clozapine.

\section{CONCLUSION}

This meta-analysis synthesised previous studies and represented the effects of smoking on the disposition of olanzapine and clozapine in a way that can be used to change the current clinical practices. Based on the results of this meta-analysis, we suggest that the doses of olanzapine and clozapine should be reduced by $30 \%$ and $50 \%$, respectively, in non-smokers compared with smokers in order to obtain an equivalent olanzapine or clozapine concentration. These results are useful as standards to change the doses of olanzapine and clozapine in clinical practice based on the patient's smoking status.

Acknowledgements The authors would like to acknowledge Kristi Bigos, Jeran Trangle, Tore Haslemo, Werner Steimer and Lionella Palego for providing them their data regarding the disposition of olanzapine or clozapine.

Contributors YT reviewed all the abstracts, reviewed all the full papers, performed the statistical analysis and wrote the paper. JS and NY-F reviewed all of the abstracts and full papers for relevance, and wrote and reviewed the submitted article.

Funding This work was supported by grants-in-aid (Nos. 23510348, 24590652 and 25860117) for scientific research from the Japanese Ministry of Education, Science, Sports and Culture.

Competing interests None.

Provenance and peer review Not commissioned; externally peer reviewed.

Data sharing statement No additional data are available.

Open Access This is an Open Access article distributed in accordance with the Creative Commons Attribution Non Commercial (CC BY-NC 3.0) license, which permits others to distribute, remix, adapt, build upon this work noncommercially, and license their derivative works on different terms, provided the original work is properly cited and the use is non-commercial. See: http:// creativecommons.org/licenses/by-nc/3.0/

\section{REFERENCES}

1. Mauri MC, Volonteri LS, Colasanti A, et al. Clinical pharmacokinetics of atypical antipsychotics: a critical review of the relationship between plasma concentrations and clinical response. Clin Pharmacokinet 2007;46:359-88.

2. Bishara D, Olofinjana $O$, Sparshatt $A$, et al. Olanzapine: a systematic review and meta-regression of the relationships between dose, plasma concentration, receptor occupancy, and response. J Clin Psychopharmacol 2013;33:329-35.

3. Si TM, Zhang YS, Shu L, et al. Use of clozapine for the treatment of schizophrenia: findings of the 2006 research on the china psychotropic prescription studies. Clin Psychopharmacol Neurosci 2012;10:99-104.

4. Bersani FS, Capra E, Minichino A, et al. Factors affecting interindividual differences in clozapine response: a review and case report. Hum Psychopharmacol 2011;26:177-87.

5. Morisano D, Wing VC, Sacco KA, et al. Effects of tobacco smoking on neuropsychological function in schizophrenia in comparison to other psychiatric disorders and non-psychiatric controls. Am J Addict 2013;22:46-53. 
6. Sagud M, Mihaljevic-Peles A, Muck-Seler D, et al. Smoking and schizophrenia. Psychiatr Danub 2009;21:371-5.

7. Citrome L, Stauffer VL, Chen L,, et al Olanzapine plasma concentrations after treatment with 10,20 , and $40 \mathrm{mg} / \mathrm{d}$ in patients with schizophrenia: an analysis of correlations with efficacy, weight gain, and prolactin concentration. J Clin Psychopharmacol 2009;29:278-83.

8. Carrillo JA, Herraiz AG, Ramos SI, et al. Role of the smoking-induced cytochrome P450 (CYP)1A2 and polymorphic CYP2D6 in steady-state concentration of olanzapine. J Clin Psychopharmacol 2003;23:119-27.

9. Schwenger E, Dumontet J, Ensom MH. Does olanzapine warrant clinical pharmacokinetic monitoring in schizophrenia? Clin Pharmacokinet 2011;50:415-28.

10. Liu HC, Chang WH, Wei FC, et al. Monitoring of plasma clozapine levels and its metabolites in refractory schizophrenic patients. Ther Drug Monit 1996;18:200-7.

11. Spina E, Avenoso A, Facciola G, et al. Relationship between plasma concentrations of clozapine and norclozapine and therapeutic response in patients with schizophrenia resistant to conventional neuroleptics. Psychopharmacology (Berl) 2000;148:83-9.

12. Mauri M, Volonteri LS, Fiorentini $A$, et al. Clinical outcome and plasma levels of clozapine and norclozapine in drug-resistant schizophrenic patients. Schizophr Res 2004;66:197-8.

13. McCarthy $\mathrm{RH}$. Seizures following smoking cessation in a clozapine responder. Pharmacopsychiatry 1994;27:210-11.

14. Skogh E, Bengtsson F, Nordin C. Could discontinuing smoking be hazardous for patients administered clozapine medication? A case report. Ther Drug Monit 1999;21:580-2.

15. Zullino DF, Delessert D, Eap CB, et al. Tobacco and cannabis smoking cessation can lead to intoxication with clozapine or olanzapine. Int Clin Psychopharmacol 2002;17:141-3.

16. Brownlowe K, Sola C. Clozapine toxicity in smoking cessation and with ciprofloxacin. Psychosomatics 2008;49:176.

17. Knobloch K, Yoon U, Vogt PM. Preferred reporting items for systematic reviews and meta-analyses (PRISMA) statement and publication bias. J Craniomaxillofac Surg 2011;39:91-2

18. Stroup DF, Berlin JA, Morton SC, et al. Meta-analysis of observational studies in epidemiology: a proposal for reporting. Meta-analysis Of Observational Studies in Epidemiology (MOOSE) group. JAMA 2000;283:2008-12.

19. DerSimonian R, Laird N. Meta-analysis in clinical trials. Control Clin Trials 1986;7:177-88.

20. Egger M, Davey Smith G, Schneider M, et al. Bias in meta-analysis detected by a simple, graphical test. BMJ 1997;315:629-34.

21. Haslemo T, Eikeseth PH, Tanum L, et al. The effect of variable cigarette consumption on the interaction with clozapine and olanzapine. Eur J Clin Pharmacol 2006;62:1049-53.

22. Nozawa M, Ohnuma T, Matsubara Y, et al. The relationship between the response of clinical symptoms and plasma olanzapine concentration, based on pharmacogenetics: Juntendo University Schizophrenia Projects (JUSP). Ther Drug Monit 2008;30:35-40.

23. Bigos KL, Pollock BG, Coley KC, et al. Sex, race, and smoking impact olanzapine exposure. J Clin Pharmacol 2008;48:157-65.

24. Laika B, Leucht S, Heres S, et al. Pharmacogenetics and olanzapine treatment: CYP1A2*1F and serotonergic polymorphisms influence therapeutic outcome. Pharmacogenomics J 2009;10:20-9.

25. Spina E, D'Arrigo C, Santoro V, et al. Effect of valproate on olanzapine plasma concentrations in patients with bipolar or schizoaffective disorder. Ther Drug Monit 2009;31:758-63.

26. Skogh E, Sjodin I, Josefsson M, et al. High correlation between serum and cerebrospinal fluid olanzapine concentrations in patients with schizophrenia or schizoaffective disorder medicating with oral olanzapine as the only antipsychotic drug. J Clin Psychopharmacol 2011;31:4-9.

27. Haslemo T, Refsum H, Molden E. The effect of ethinylestradiolcontaining contraceptives on the serum concentration of olanzapine and N-desmethyl olanzapine. Br J Clin Pharmacol 2011;71:611-15.

28. Dettling M, Sachse C, Brockmoller J, et al. Long-term therapeutic drug monitoring of clozapine and metabolites in psychiatric in- and outpatients. Psychopharmacology (Berl) 2000;152:80-6.

29. Palego L, Biondi L, Giannaccini G, et al. Clozapine, norclozapine plasma levels, their sum and ratio in 50 psychotic patients: influence of patient-related variables. Prog Neuropsychopharmacol Biol Psychiatry 2002;26:473-80.
30. van der Weide J, Steijns LS, van Weelden MJ. The effect of smoking and cytochrome P450 CYP1A2 genetic polymorphism on clozapine clearance and dose requirement. Pharmacogenetics 2003;13:169-72.

31. Knadler MP, Lobo E, Chappell J, et al. Duloxetine: clinical pharmacokinetics and drug interactions. Clin Pharmacokinet 2011;50:281-94.

32. Nathisuwan S, Dilokthornsakul P, Chaiyakunapruk $\mathrm{N}$, et al. Assessing evidence of interaction between smoking and warfarin: a systematic review and meta-analysis. Chest 2011;139:1130-9.

33. Wahawisan J, Kolluru S, Nguyen T, et al. Methadone toxicity due to smoking cessation-a case report on the drug-drug interaction involving cytochrome P450 isoenzyme 1A2. Ann Pharmacother 2011;45:e34.

34. Iqbal J, Sun L, Cao J, et al. Smoke carcinogens cause bone loss through the aryl hydrocarbon receptor and induction of Cyp1 enzymes. Proc Natl Acad Sci USA 2013;110:11115-20.

35. Callaghan JT, Bergstrom RF, Ptak LR, et al. Pharmacokinetic and pharmacodynamic profile. Clin Pharmacokinet 1999;37:177-93.

36. Remington G, Agid O, Foussias G, et al. Clozapine and therapeutic drug monitoring: is there sufficient evidence for an upper threshold? Psychopharmacology (Berl) 2013;225:505-18.

37. Li LJ , Shang DW, Li WB, et al. Population pharmacokinetics of clozapine and its primary metabolite norclozapine in Chinese patients with schizophrenia. Acta Pharmacol Sin 2012;33:1409-16.

38. Weiss U, Marksteiner J, Kemmler G, et al. Effects of age and sex on olanzapine plasma concentrations. J Clin Psychopharmacol 2005;25:570-4.

39. Haring C, Fleischhacker WW, Schett P, et al. Influence of patient-related variables on clozapine plasma levels. $A m \mathrm{~J}$ Psychiatry 1990;147:1471-5.

40. Diaz FJ, de Leon J, Josiassen RC, et al. Plasma clozapine concentration coefficients of variation in a long-term study. Schizophr Res 2005;72:131-5.

41. Diaz FJ, Santoro V, Spina E, et al. Estimating the size of the effects of co-medications on plasma clozapine concentrations using a model that controls for clozapine doses and confounding variables. Pharmacopsychiatry 2008;41:81-91.

42. $\mathrm{Ng} \mathrm{W}$, Uchida $\mathrm{H}$, Ismail $\mathrm{Z}$, et al. Clozapine exposure and the impact of smoking and gender: a population pharmacokinetic study. Ther Drug Monit 2009;31:360-6.

43. Gex-Fabry M, Balant-Gorgia AE, Balant LP. Therapeutic drug monitoring of olanzapine: the combined effect of age, gender smoking, and comedication. Ther Drug Monit 2003;25:46-53.

44. Lee ST, Ryu S, Kim SR, et al. Association study of 27 annotated genes for clozapine pharmacogenetics: validation of preexisting studies and identification of a new candidate gene, ABCB1, for treatment response. J Clin Psychopharmacol 2012;32:441-8.

45. Theisen FM, Haberhausen M, Schulz E, et al. Serum levels of olanzapine and its N-desmethyl and 2-hydroxymethyl metabolites in child and adolescent psychiatric disorders: effects of dose, diagnosis, age, sex, smoking, and comedication. Ther Drug Monit 2006;28:750-9.

46. Patel MX, Bowskill S, Couchman L, et al. Plasma olanzapine in relation to prescribed dose and other factors: data from a therapeutic drug monitoring service, 1999-2009. J Clin Psychopharmacol 2011;31:411-17.

47. Soderberg MM, Haslemo T, Molden E, et al. Influence of FMO1 and 3 polymorphisms on serum olanzapine and its $\mathrm{N}$-oxide metabolite in psychiatric patients. Pharmacogenomics J 2013;13:544-50.

48. Botts S, Diaz FJ, Santoro V, et al. Estimating the effects of co-medications on plasma olanzapine concentrations by using a mixed model. Prog Neuropsychopharmacol Biol Psychiatry 2008;32:1453-8.

49. Bergemann N, Frick A, Parzer P, et al. Olanzapine plasma concentration, average daily dose, and interaction with co-medication in schizophrenic patients. Pharmacopsychiatry 2004;37:63-8.

50. Soderberg MM, Dahl ML. Pharmacogenetics of olanzapine metabolism. Pharmacogenomics 2013;14:1319-36.

51. Plowchalk DR, Rowland Yeo K. Prediction of drug clearance in a smoking population: modeling the impact of variable cigarette consumption on the induction of CYP1A2. Eur J Clin Pharmacol 2012;68:951-60.

52. Leucht S, Kissling W, Davis JM. Second-generation antipsychotics for schizophrenia: can we resolve the conflict? Psychol Med 2009;39:1591-602. 